\section{Is Iron the New Ruthenium?}

\author{
Oliver S. Wenger*[a]
}

Abstract: Ruthenium complexes with polypyridine ligands are very popular choices for applications in photophysics and photochemistry, for example lighting, sensing, solar cells, and photoredox catalysis. There is a long-standing interest in replacing ruthenium by iron, because ruthenium is rare and expensive whereas iron is comparatively abundant and cheap. However, it is very difficult to obtain iron complexes with an electronic structure similar to that of ruthenium(II) polypyridines. The latter typically have a long-lived excited state with pronounced charge transfer character between the ruthenium metal and the ligands. These metal-to-ligand charge transfer (MLCT) excited states can be luminescent with typical lifetimes in the range of $100 \mathrm{~ns}$ to $1000 \mathrm{~ns}$, and the electrochemical properties are drastically altered during this time. These properties make ruthenium(II) polypyridine complexes so well suited for the abovementioned applications. In iron(II) complexes the MLCT states can be deactivated extremely rapidly (ca. $50 \mathrm{fs}$ ) by energetically lower lying metal-centered excited states. Luminescence is then no longer emitted, and the MLCT lifetimes become much too short for most applications. Very recently, there has been substantial progress on extending the lifetimes of MLCT states in iron(II) complexes, and the first examples of luminescent iron complexes have just been reported. Interestingly, these are iron(III) complexes with a completely different electronic structure than the commonly targeted iron(II) compounds, and this could mark the beginning of a paradigm change in research on photoactive earth-abundant metal complexes. After outlining some of the fundamental challenges, this invited Concept article discusses the key strategies used so far to enhance the photophysical and photochemical properties of iron complexes, and it discusses recent conceptual breakthroughs.

\section{Commonalities and differences in the photophysics of $\mathrm{Ru}^{\prime \prime}$ and $\mathrm{Fe}^{\prime \prime}$ polypyridine complexes}

Most chemical compounds have only very short-lived excited states and do not luminesce after excitation with visible or UV light. Instead, they turn the absorbed energy simply into heat. To obtain luminescent substances with long-lived excited states, a very stringent set of criteria must be fulfilled, and this limits the available chemical space for photophysically and photochemically attractive compounds severely. This is the main reason why certain classes of substances receive much more attention from spectroscopists and photochemists than others. In coordination chemistry, complexes with a metal having a $4 d^{6}$ or $5 d^{6}$ valence

[a] Prof. Dr. O. S. Wenger

Department of Chemistry, University of Basel

St. Johanns-Ring 19, 4056 Basel (Switzerland)

E-mail: oliver.wenger@unibas.ch electron configuration represent such a privileged class of compounds. ${ }^{[1]}$ In the vast majority of cases explored to date, this includes precious elements with Ru", Os", Ir"l and Re' as the most popular examples. When these metal cations are ligated to organic chelating agents possessing energetically low-lying unoccupied $\pi^{\star}$ orbitals, then emissive MLCT excited states with long lifetimes can result.
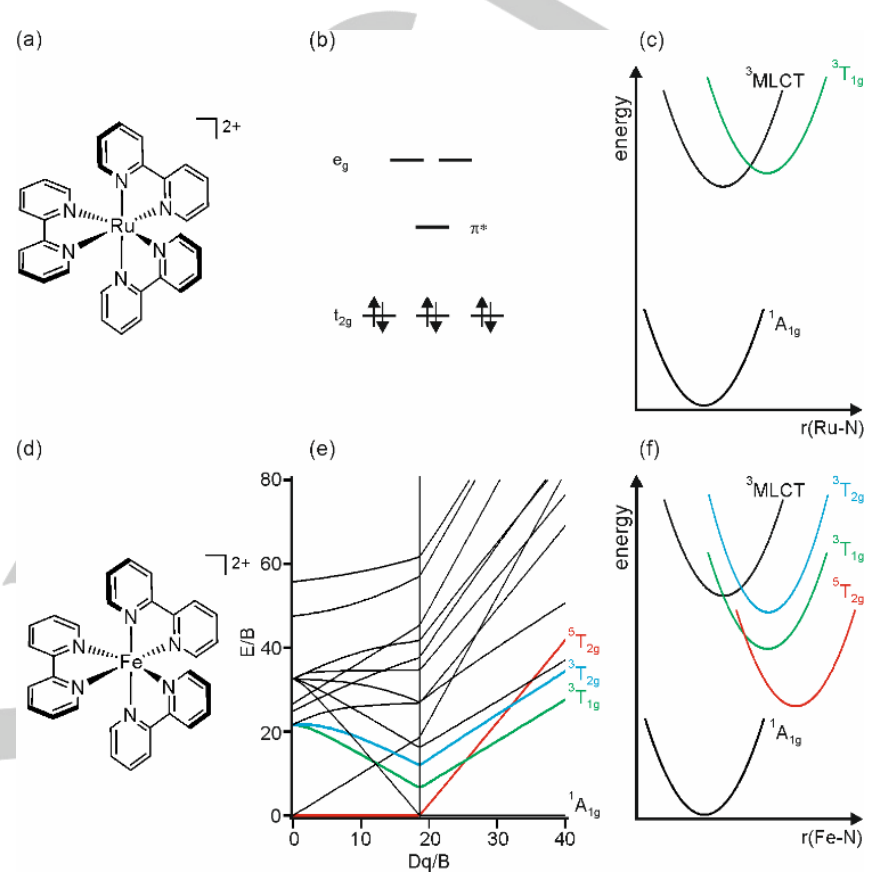

Figure 1. (a) Molecular structure of $\left[R u(b p y)_{3}\right]^{2+} ;\left(\right.$ b) the low-spin $d^{6}$ electron configuration in $\mathrm{O}_{\mathrm{n}}$ symmetry including a low-lying ligand-based $\pi^{\star}$ orbital in addition to the metal-based $t_{2 g}$ and $e_{g}$ orbitals; (c) simplified potential energy diagram with the key electronic states in $\left[\mathrm{Ru}(\mathrm{bpy})_{3}\right]^{2+} ;$ (d) molecular structure of $\left[\mathrm{Fe}(\mathrm{bpy})_{3}\right]^{2+} ;$ (e) Tanabe-Sugano diagram for the $\mathrm{d}^{6}$ electron configuration; (f) simplified potential energy diagram with the key electronic states in $\left[\mathrm{Fe}(\mathrm{bpy})_{3}\right]^{2+}$.

The $\left[\mathrm{Ru}(\mathrm{bpy})_{3}\right]^{2+}$ complex (bpy $=2,2$ '-bipyridine) (Figure 1a) is the prototype of this substance class, and its simplified electronic structure is illustrated in Figure 1b/c. An important simplification is that octahedral symmetry is assumed even though the actual symmetry is lower. In the orbital picture of Figure $1 \mathrm{~b}$, the 6 valence electrons are all paired in three metal-centered orbitals of $t_{2 g}$ symmetry, whilst the $e_{g}$ orbitals are energetically so high that they remain empty, resulting is a low-spin $d^{6}$ electron configuration. Owing to the strong ligand field in $4 d$ and $5 d$ metals, the $t_{2 g}-e_{g}$ ligand splitting is in fact so large that the $\pi^{\star}$ orbitals of polypyridine ligands are energetically below the metal $e_{g}$ orbitals. Consequently, the lowest electronically excited state is of MLCT type with one of the $t_{2 g}$ electrons promoted to the ligand $\pi^{*}$ orbital. Notably this is a triplet state, because after initial population of singlet excited states, the heavy metal enables very rapid intersystem crossing. ${ }^{[2]}$ In the ${ }^{3} \mathrm{MLCT}$ state, the Ru- $\mathrm{N}$ distances are only weakly elongated with respect to the ${ }^{1} A_{1 g}$ electronic ground state, manifesting in ${ }^{3} \mathrm{MLCT}$ and ${ }^{1} \mathrm{~A}_{1 g}$ potential wells with small mutual horizontal displacement in Figure $1 \mathrm{c}^{[3]}$ The large 
(vertical) energy gap between the two potentials combined with their small mutual displacement along the Ru-N normal coordinate favors radiative excited-state relaxation. This is in competition with nonradiative deactivation of the ${ }^{3} \mathrm{MLCT}$ state via the metal-centered (MC) ${ }^{3} \mathrm{~T}_{1 \mathrm{~g}}$ state derived from the excitation of $a_{2 g}$-electron into an $\mathrm{e}_{\mathrm{g}}$-orbital. The potential well of that ${ }^{3} \mathrm{MC}$ state (green in Figure 1c) is markedly displaced along the Ru-N coordinate (typically the $\mathrm{a}_{1 \mathrm{~g}}$ normal coordinate) because one electron has moved from a largely non-bonding to an antibonding orbital. This horizontal displacement opens a pathway for the ${ }^{3} \mathrm{MLCT}$ excited-state population to cross over a certain barrier into the ${ }^{3} \mathrm{~T}_{1 \mathrm{~g}}$ state, and from there onwards to the ${ }^{1} \mathrm{~A}_{1 \mathrm{~g}}$ ground state. ${ }^{[4]}$ In $\left[\mathrm{Ru}(\mathrm{tpy})_{2}\right]^{2+}$ (tpy $=2,2^{\prime}: 6^{\prime}, 2^{\prime \prime}$-terpyridine) the ${ }^{3} \mathrm{~T}_{1 \mathrm{~g}}$ state is markedly lower than in $\left[\mathrm{Ru}(\mathrm{bpy})_{3}\right]^{2+}$, and this is the main reason why $\left[\mathrm{Ru}(\mathrm{tpy})_{2}\right]^{2+}$ is essentially non-emissive at room temperature in fluid solution whilst $\left[\mathrm{Ru}(\mathrm{bpy})_{3}\right]^{2+}$ has a decent luminescence quantum yield under such conditions..$^{[5]}$ The lower energy of the ${ }^{3} \mathrm{~T}_{1 \mathrm{~g}}$ state in $\left[\mathrm{Ru}(\mathrm{tpy})_{2}\right]^{2+}$ is a direct consequence of the weaker ligand field caused by tpy compared to bpy, due to smaller N-Ru$\mathrm{N}$ angles.

In $\mathrm{Fe}^{\mathrm{Il}}$ complexes such as $\left[\mathrm{Fe}(\mathrm{bpy})_{3}\right]^{2+}$ (Figure 1d), the ligand field is much weaker even than in $\left[\mathrm{Ru}(\mathrm{tpy})_{2}\right]^{2+}$ because the radial distribution of the six $3 \mathrm{~d}$ electrons is closer to the metal core than that of the $4 \mathrm{~d}$ electrons in Ru". Consequently, the ${ }^{3} \mathrm{~T}_{1 \mathrm{~g}}$ state as well as another metal-centered excited state $\left({ }^{5} \mathrm{~T}_{2 \mathrm{~g}}\right)$ is below the ${ }^{3} \mathrm{MLCT}$ state in $\left[\mathrm{Fe}(\mathrm{bpy})_{3}\right]^{2+}$ (Figure $\left.1 \mathrm{f}\right)$, and three other MC states $\left({ }^{3} \mathrm{~T}_{2 g},{ }^{1} \mathrm{~T}_{1 \mathrm{~g}},{ }^{1} \mathrm{~T}_{2 \mathrm{~g}}\right)$ are energetically close (not all included in Figure 1f). ${ }^{\left[{ }^{6]}\right.}$ In this situation the ${ }^{3} \mathrm{MLCT}$ state is deactivated within ca. 50 fs in essentially barrierless fashion, followed by vibrational cooling on a timescale of a few ps. ${ }^{[7]} \mathrm{The}^{5} \mathrm{~T}_{2 \mathrm{~g}}$ state is non-luminescent yet fairly long-lived (ca. 650 ps), and this has been exploited in photochemical contexts, ${ }^{[8]}$ but it would be much more desirable to obtain a long-lived luminescent MLCT state resembling that of $\left[\mathrm{Ru}(\mathrm{bpy})_{3}\right]^{2+}$. To date, this has not yet been achieved with iron. There are two fairly obvious ways to work toward that goal: The ${ }^{3} \mathrm{MLCT}$ state can be energetically stabilized and the metalcentered states should be pushed to higher energies. Lowering of the MLCT state is only viable within the limits of the rules dictated by the energy-gap law, ${ }^{[9]}$ which basically states that the smaller the energy difference between the ${ }^{3} \mathrm{MLCT}$ and the ${ }^{1} \mathrm{~A}_{1 \mathrm{~g}}$ state gets, the more efficient direct nonradiative relaxation to the ground state becomes. The effect of an increase in ligand field strength is illustrated by the Tanabe-Sugano diagram for the $d^{6}$-electron configuration (Figure 1e). The energies of the ${ }^{3} \mathrm{~T}_{1 \mathrm{~g}}$ and ${ }^{5} \mathrm{~T}_{2 \mathrm{~g}}$ key states raise with increasing ratio between ligand field strength parameter $(\mathrm{Dq})$ and Racah-parameter $(\mathrm{B})$, the latter being a measure for covalence of the metal-ligand bond. The energy of the ${ }^{5} \mathrm{~T}_{2 g}$ state (red) is roughly twice as strongly dependent on the ratio $\mathrm{Dq} / \mathrm{B}$ as the ${ }^{3} \mathrm{~T}_{1 \mathrm{~g}}$ state (green), because it involves the excitation of two electrons into antibonding $e_{g}$ orbitals rather than one, manifesting also in the stronger horizontal displacement of the ${ }^{5} \mathrm{~T}_{2 g}$ potential well in Figure 1f. Depending on the ligands, either the ${ }^{5} \mathrm{~T}_{2 g}$ or the ${ }^{3} \mathrm{~T}_{1 g}$ state is therefore usually the lowest electronically excited state in low-spin Fe" complexes. Increasing the ligand field strength is the key strategy followed by most researchers, and there are various ways to achieve this as discussed below.
In single configurational coordinate diagrams such as those in Figure 1c/f, sometimes harmonic potentials are used for simplicity even though there can be significant degrees of anharmonicity. Usually identical force constants are assumed for the electronic ground state and the different types of excited states, and this represents a further simplification. The normal coordinate on the $x$-axis often represents an essentially totally symmetrical $\left(a_{1 g}\right)$ distortion, but the types of relevant nuclear coordinates can be different from one compound to another. ${ }^{[10]}$

Each of the following 6 sections discusses one of 6 key concepts to achieve long-lived MLCT excited states in Fe"l complexes. This includes the creation of highly symmetric ligand fields (Figure 2a), the use of push-pull ligand sets (Figure $2 b$ ), highly strained complexes giving access to ${ }^{5} \mathrm{MLCT}$ states (Figure 2c), exploitation of strong $\sigma$-donation provided by NHC ligands (Figure 2d), combined $\sigma$ - and $\pi$-donation by cyclometalating ligands (Figure $2 \mathrm{e})$, and the use of mesoionic carbenes as combined $\sigma$-donor, $\pi$ acceptor ligands (Figure 2f). Subsequently, the recent conceptual breakthrough leading to emissive Fe $\mathrm{F}^{\text {III }}$ complexes is highlighted, and some alternatives based on other Earth-abundant metal elements are discussed very briefly. (a)

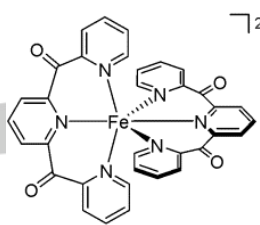

Concept I:

high-symmetry,

strong $\pi$-acceptor ligands

(McCusker)

(d)

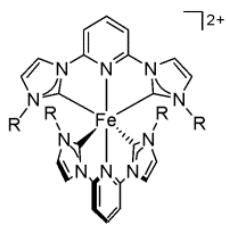

Concept IV:

strong $\sigma$-donation, $\mathrm{NHC}$ ligands

(Wärnmark, Gros)

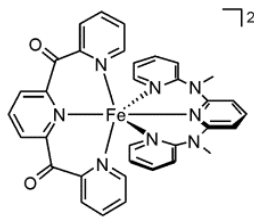

Concept II: high-symmetry, push-pull ligand se (Heinze)

(e)

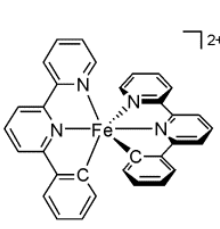

Concept V:

$\sigma$ - and $\pi$-donation, cyclometalating ligands

(Dixon, Jakubikova) (c)

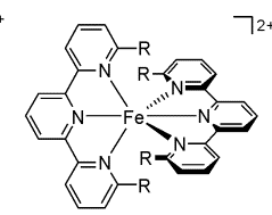

Concept III:

high strain,

access ${ }^{5}$ MLCT

(Damrauer)

(f)

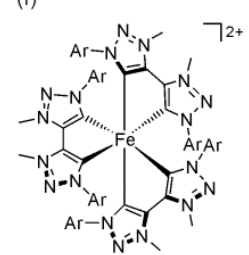

Concept VI:

strong $\sigma$-donation \& mesoionic carbene ligands

(Wärnmark)
Figure 2. Key strategies and concepts for obtaining $\mathrm{Fe}^{\text {Il }}$ complexes with longlived MLCT states, along with exemplary molecular structures: (a) $\left[\mathrm{Fe}(\mathrm{dcpp})_{2}\right]^{2+;} ;{ }^{[11]} \quad$ (b) $[\mathrm{Fe}(\mathrm{dcpp})(\mathrm{ddpd})]^{2+;[12]} \quad$ (c) $\left[\mathrm{Fe}(\mathrm{dftpy})_{2}\right]^{2+}(\mathrm{R}=\mathrm{F})$, $\left[\mathrm{Fe}(\text { dctpy })_{2}\right]^{2+}(\mathrm{R}=\mathrm{Cl}),\left[\mathrm{Fe}(\mathrm{dbtpy})_{2}\right]^{2+}(\mathrm{R}=\mathrm{Br}) ;{ }^{[13]}(\mathrm{d})\left[\mathrm{Fe}\left(\mathrm{C}_{\mathrm{NHC}}-\mathrm{N}_{\text {pyridine- }}-\mathrm{C}_{\mathrm{NHC}}\right)_{2}\right]^{2+}$ with $\mathrm{R}=\mathrm{CH}_{3},{ }^{[14]} \mathrm{R}={ }^{t} \mathrm{Bu},{ }^{[15]} \mathrm{R}={ }^{i} \mathrm{Pr} ;{ }^{[16]}$ (e) bis(terdentate) complexes with

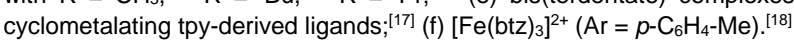

\section{Concept I: High symmetry}

One way to enhance the ligand field is to design chelating agents that permit coordination of $\mathrm{Fe}^{\text {II }}$ with bond angles as close as 
possible to those of the ideal octahedral coordination geometry, i. e., $180^{\circ}$ for $\mathrm{N}-\mathrm{Fe}-\mathrm{N}$ trans angles. This maximizes the overlap between the metal and ligand orbitals contributing to the coordination bond. McCusker and coworkers used a tridentate ligand with three pyridine binding motifs linked via carbonylgroups, resulting in $\mathrm{N}-\mathrm{Fe}-\mathrm{N}$ trans angles of $178.3^{\circ}$ in the $\left[\mathrm{Fe}(\mathrm{dcpp})_{2}\right]^{2+}$ complex (Figure 2a). For reference, in $\left[\mathrm{Ru}(\mathrm{tpy})_{2}\right]^{2+}$ the N-Ru-N trans angles are $158.6^{\circ},{ }^{[5]}$ hence the bite angle adoptable for dcpp is much more favorable. Perhaps even more significant is the electron-withdrawing nature of the carbonylgroups, leading to an energetic stabilization of the lowest $\pi^{\star}$ orbital of the dcpp ligand. This leads to better energetic match with the filled $t_{2 g}$ orbitals of the Fell center, which in turn causes increased metal-ligand orbital mixing and stabilization of the $t_{2 g}$ orbitals (Figure $3 c$ ), i. e., dcpp is a strong $\pi$ acceptor ligand. Thus, the ligand field in $\left[\mathrm{Fe}(\mathrm{dcpp})_{2}\right]^{2+}$ is roughly $600 \mathrm{meV}$ stronger than in $\left[\mathrm{Fe}(\mathrm{tpy})_{2}\right]^{2+}$, manifesting in an unusual blue color (purple is more typical for $\mathrm{Fe}^{\text {Il }}$ polypyridines) and a substantially higher electrochemical potential for (metal-based) one-electron oxidation In acetonitrile at room temperature, $\left[\mathrm{Fe}(\mathrm{dcpp})_{2}\right]^{2+}$ has an excited state with a lifetime of $280 \mathrm{ps}$, and it is not a priori clear what type of ligand-field state this is. In $\left[\mathrm{Fe}(\mathrm{tpy})_{2}\right]^{2+}{ }^{5} \mathrm{~T}_{2 \mathrm{~g}}$ is the lowest excited state, decaying with a lifetime of 960 ps under identical conditions ${ }^{[11]}$ Possibly, the ligand field in $\left[\mathrm{Fe}(\mathrm{dcpp})_{2}\right]^{2+}$ is so strong that ${ }^{3} \mathrm{~T}_{1 \mathrm{~g}}$ instead of ${ }^{5} \mathrm{~T}_{2 \mathrm{~g}}$ is lowest (green vs. red in Figure $1 \mathrm{e}$ ), and this could be the origin of the faster excited state decay, for two key reasons: (i) The electronic coupling between ${ }^{3} \mathrm{~T}_{1 g}$ and ${ }^{1} \mathrm{~A}_{1 g}$ is likely stronger than that between ${ }^{5} \mathrm{~T}_{2 g}$ and ${ }^{1} \mathrm{~A}_{1 g}$ because of the smaller change of net spin, and (ii) the reorganization energy associated with the transition from ${ }^{3} \mathrm{~T}_{1 \mathrm{~g}}$ to ${ }^{1} \mathrm{~A}_{1 \mathrm{~g}}$ is smaller because it involves the relaxation of a single $e_{g}$ electron to a $t_{2 g}$ orbital, whereas the transition from ${ }^{5} \mathrm{~T}_{2 g}$ to ${ }^{1} \mathrm{~A}_{1 \mathrm{~g}}$ involves the relaxation of two electrons from antibonding $e_{g}$ to formally non-bonding $t_{2 g}$ orbitals. Both of these effects are expected to make relaxation from the ${ }^{3} \mathrm{~T}_{1 \mathrm{~g}}$ faster than from the ${ }^{5} \mathrm{~T}_{2 \mathrm{~g}}$, in line with the observation that the excited state of $\left[\mathrm{Fe}(\mathrm{dcpp})_{2}\right]^{2+}$ decays more rapidly than the ${ }^{5} \mathrm{~T}_{2 \mathrm{~g}}$ state of $\left[\mathrm{Fe}(\mathrm{tpy})_{2}\right]^{2+}$ (280 vs. $960 \mathrm{ps}$ ).

The $\left[\mathrm{Fe}(\mathrm{dcpp})_{2}\right]^{2+}$ study by McCusker and coworkers very nicely illustrates the concepts of coordination geometry optimization and ligand $\pi^{\star}$ acceptor property tuning. Computational work by Jakubikova and coworkers supports the interpretation of these experimental results, and further suggested that replacement of the central pyridine unit of the dcpp ligand by a five-membered $\mathrm{NHC}$ or a cyclometalating phenyl unit would provide an even stronger ligand field. ${ }^{[19]}$

\section{Concept II: Push-pull systems with high symmetry}

Heinze and coworkers combined McCusker's electronwithdrawing dcpp with the electron-rich ddpd ligand to obtain the heteroleptic [Fe(dcpp)(ddpd)] ${ }^{2+}$ complex (Figure 2b). ${ }^{[12]}$ Like dcpp, the ddpd ligand is able to chelate $\mathrm{Fe}^{\mathrm{ll}}$ in terdentate fashion with favorable N-Fe-N angles, but with amine- instead of carbonylgroups in the backbone it is much more electron-rich. ${ }^{[20]}$ The aim was to exploit the resulting push-pull ligand combination to lower the ${ }^{1 / 3} \mathrm{MLCT}$ manifold of $\mathrm{Fe}^{11}$ complexes while at the same time raising the ${ }^{3} \mathrm{~T}_{1 \mathrm{~g}}$ and ${ }^{5} \mathrm{~T}_{2 \mathrm{~g}}$ states through increased metal-ligand orbital overlap facilitated by the favorable bite angles of these two particular ligands. $[\mathrm{Fe}(\mathrm{dcpp})(\mathrm{ddpd})]^{2+}$ exhibits low-lying absorption bands with maxima at 585 and $559 \mathrm{~nm}$ of mixed MLCT and ligand-to-ligand charge transfer (LLCT) character (ddpd $\rightarrow$ dcpp). However, following excitation at $500 \mathrm{~nm}$ picosecond transient absorption spectroscopy fails to provide any evidence for excited-state absorptions that would be clearly attributable to MLCT or LLCT states, and it was concluded that internal conversion to a metal-centered state occurs instead. The observable ground state recovery with a time constant of $548 \mathrm{ps}$ was tentatively attributed to the ${ }^{3} \mathrm{~T}_{1 \mathrm{~g}}$ state, ${ }^{[12]}$ following McCusker's interpretation that dcpp induces a ligand field strength approaching the ${ }^{5} \mathrm{~T}_{2 g} /{ }^{3} \mathrm{~T}_{1 \mathrm{~g}}$ crossing point (Figure 1e) or possibly even exceeding it. ${ }^{[11]}$ The approach of obtaining luminescent LLCT (instead of MLCT) states in push-pull complexes with Fe" seems very promising with a variant of ddpd in which the amines are not methylated but merely bear an $\mathrm{H}$-atom. ${ }^{[21]}$
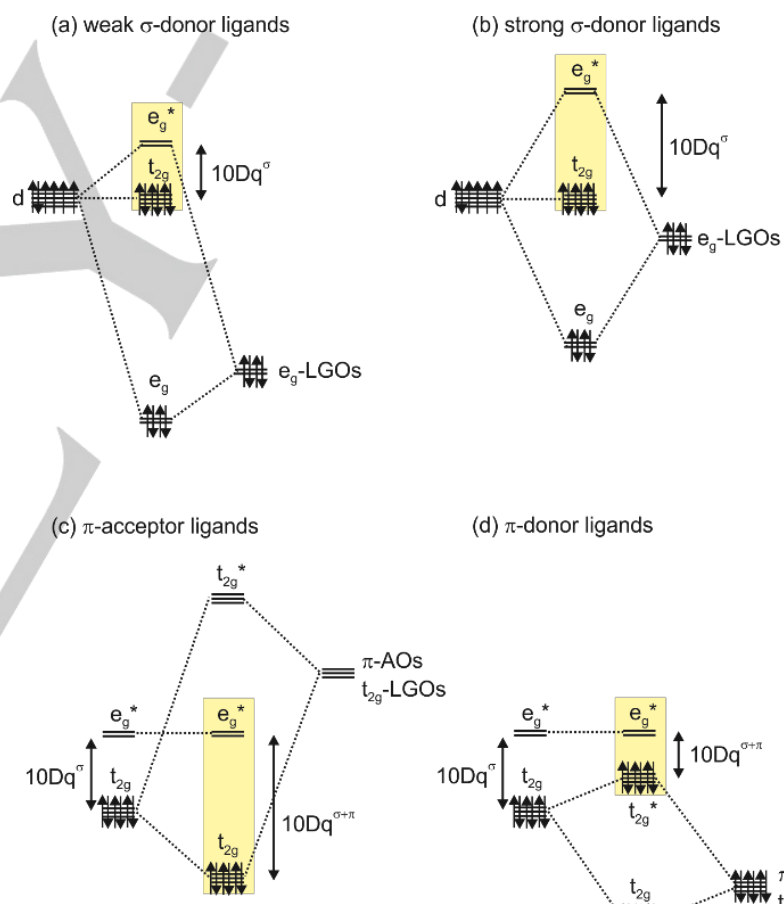

(d) $\pi$-donor ligands

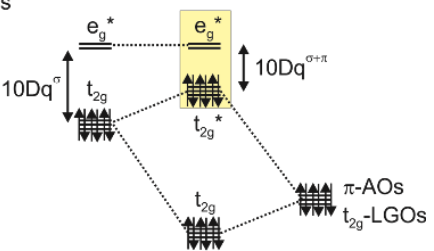

Figure 3. Ligand field effects depending on the type of bonding interactions between metal d-orbitals and ligand group orbitals (LGOs) or atomic orbitals (AOs). The vertical axes are energy axes. The key point is the magnitude of the ligand field strength $(10 \mathrm{Dq})$, given as the energy difference between $t_{2 g}$ and $e_{g}$ orbitals (marked in yellow).

\section{Concept III: Accessing ${ }^{5} \mathrm{MLCT}$ states in strained low-spin complexes}

Damrauer and coworkers explored a fundamentally different concept in homoleptic Fe" complexes with tpy ligands which are halogenated at the 6- and 6"-positions (Figure 2c). ${ }^{[13]}$ The ligand 
field in the chloro- and bromo-substituted $\left[\mathrm{Fe}(\mathrm{dctpy})_{2}\right]^{2+}$ and $\left[\mathrm{Fe}(\mathrm{dbtpy})_{2}\right]^{2+}$ complexes is substantially weaker than in the $\left[\mathrm{Fe}(\mathrm{tpy})_{2}\right]^{2+}$ parent compound, due to repulsive interactions between the halogen atoms from one tpy ligand with the second (opposing) tpy. Consequently, ${ }^{5} \mathrm{~T}_{2 g}$ rather than ${ }^{1} \mathrm{~A}_{1 \mathrm{~g}}$ is their electronic ground state, as expected for weak-field ligands (Figure 1e). In the fluoro-substituted $\left[\mathrm{Fe}(\mathrm{dftpy})_{2}\right]^{2+}$ complex, ${ }^{5} \mathrm{~T}_{2 \mathrm{~g}}$ and ${ }^{1} \mathrm{~A}_{1 \mathrm{~g}}$ are populated in a ratio of $97 \%: 3 \%$ at room temperature. Thus, it is possible to excite each one of the three complexes into a spinallowed ${ }^{5} \mathrm{~T}_{2 \mathrm{~g}} \rightarrow{ }^{5} \mathrm{MLCT}$ transition, and the subsequent decay of the ${ }^{5} \mathrm{MLCT}$ state (or ${ }^{7} \mathrm{MLCT}$ in the event of intersystem crossing) can be monitored. This is fundamentally different from the ${ }^{3} \mathrm{MLCT}$ states which are typically populated via intersystem crossing after ${ }^{1} \mathrm{~A}_{1 \mathrm{~g}} \rightarrow{ }^{1} \mathrm{MLCT}$ excitation of low-spin Fell complexes. The key finding is that the ${ }^{5 / 7} \mathrm{MLCT}$ lifetime increases from 14.0 to 16.0 and 17.4 ps along the $\mathrm{F}-, \mathrm{Cl}$ - and $\mathrm{Br}$-series of complexes (in acetonitrile at room temperature) ${ }^{[13 a]}$ Direct nonradiative passage between the ${ }^{5 / 7} \mathrm{MLCT}$ and the ${ }^{5} \mathrm{~T}_{2 g}$ states seems unlikely, and a decay path involving the ${ }^{3} \mathrm{~T}_{1 \mathrm{~g}}$ (or other nearby ${ }^{3} \mathrm{MC}$ states) is more plausible. The energy of the relevant ${ }^{3} \mathrm{MC}$ state should be fairly sensitive to size of the halogen substituent, because this state derives from an electron configuration with greater net metalligand bonding character than the ${ }^{5 / 7} \mathrm{MLCT}$ and ${ }^{5} \mathrm{~T}_{2 \mathrm{~g}}$ states (Figure 1f). The observation of slower ${ }^{5 / 7} \mathrm{MLCT}$ decay with larger halogen size is compatible with an increasing barrier to interconversion from ${ }^{5 / 7} \mathrm{MLCT}$ to ${ }^{3} \mathrm{MC}$, caused by a shift of the ${ }^{3} \mathrm{MC}$ potential well to higher energies, closer to the ${ }^{5 / 7} \mathrm{MLCT}$ potential well (red circle in Figure 4). Moreover, the larger the halogen atom, the more difficult it is energetically for the ${ }^{5 / 7} \mathrm{MLCT}$ state to adopt geometries needed for conversion to the ${ }^{3} \mathrm{MC}$ state. In other words, the halogen exchange along the series $\mathrm{F}, \mathrm{Cl}, \mathrm{Br}$ leads to an increase of the reorganization energy for internal conversion, and this could contribute to the ${ }^{5 / 7} \mathrm{MLCT}$ lifetime lengthening. The key concept pursued in this work can be described as the exploitation of interligand steric interactions to control relative state energies and to limit conformational dynamics. ${ }^{[13]}$ The increase of the ${ }^{5 / 7} \mathrm{MLCT}$ lifetime along the $\mathrm{F}$-, $\mathrm{Cl}$-, $\mathrm{Br}$-series of $\mathrm{Fe}^{\mathrm{ll}}$ complexes is somewhat reminiscent of the counter heavy-atom effect observed for intersystem crossing rates in $\mathrm{Re}^{1}$ complexes. ${ }^{[22]}$ (a)

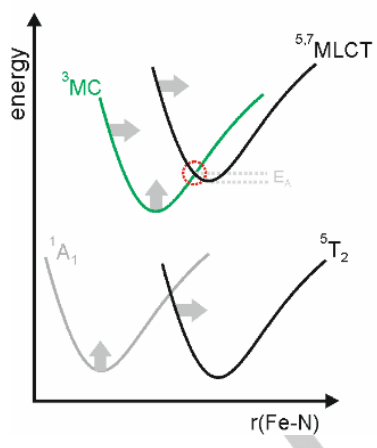

(b)

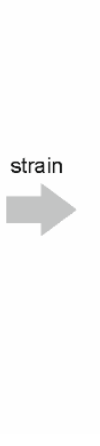

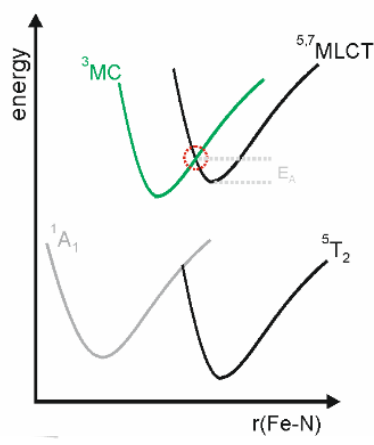

Figure 4. Illustration of the effects of increasing steric hindrance along the series $\left[\mathrm{Fe}(\mathrm{dftpy})_{2}\right]^{2+},\left[\mathrm{Fe}(\mathrm{dctpy})_{2}\right]^{2+},\left[\mathrm{Fe}(\mathrm{dbtpy})_{2}\right]^{2+}(\mathrm{R}=\mathrm{F}, \mathrm{Cl}, \mathrm{Br}$ in Figure $2 \mathrm{c})$ on the relevant potential energy surfaces ${ }^{[13]}$ (a) Comparatively little strain $(R=F)$; (b) comparatively strong strain $(R=B r)$. The activation energy $\left(E_{A}\right)$ for crossing from ${ }^{5} \mathrm{MLCT}$ to ${ }^{3} \mathrm{MC}$ increases from (a) to (b). Grey arrows in (a) mark the effects of increasing strain coming into effect in (b).

\section{Concept IV: Enhancement of ligand-field strength with $\sigma$-donating NHC ligands}

In McCusker's [Fe(dcpp) $\left.)_{2}\right]^{2+}$ complex (Figure 2a) the pronounced $\pi$-acceptor properties of the dcpp ligand cause a strong ligand field by stabilizing the $t_{2 g}$ orbitals (see above). A complementary strategy to increasing the ligand field strength is to destabilize the $e_{g}$ orbitals with strongly $\sigma$-donating ligands (Figure $\left.3 a / b\right)$. This is the key concept behind the use of $\mathrm{N}$-heterocyclic carbene (NHC) ligands for Fe" complexes (Figure 2d), as first investigated in the context of obtaining long-lived ${ }^{3} \mathrm{MLCT}$ excited states by Wärnmark and coworkers. ${ }^{[14]}$ This very promising area has been reviewed, ${ }^{[23]}$ and several different research groups have made important recent contributions. (a)

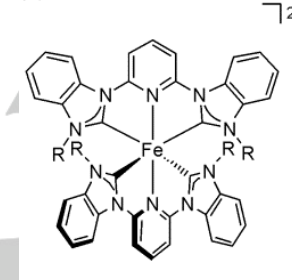

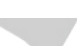

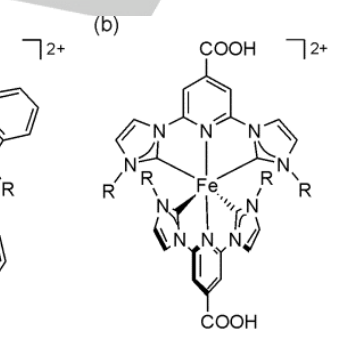

(c)
Figure 5. Molecular structures of Fell complexes with $\mathrm{NHC}$ ligands: (a) benzimidazolylidene-based analog of the complex in Figure $2 \mathrm{~d}\left(\mathrm{R}=\mathrm{CH}_{3}\right)_{;}^{[24]}(\mathrm{b})$ carboxyl-substituted analog of the prototype complex in Figure $2 \mathrm{~d}\left(\mathrm{R}=\mathrm{CH}_{3}\right) ;$ ${ }^{25]}$ (c) heteroleptic Fe" NHC-tpy complex (dipp = diisopropylphenyl). ${ }^{[16]}$

In the pioneering study, a ${ }^{3} \mathrm{MLCT}$ lifetime of $9 \mathrm{ps}$ (in $\mathrm{CH}_{3} \mathrm{CN}$ at room temperature) was reported for a homoleptic complex with the terdentate 2,6-bis(imidzol-2-ylidene)pyridine ligand (Figure $2 \mathrm{~d}$ ), and this was at that point (2013) the longest known ${ }^{3} \mathrm{MLCT}$ lifetime for $\mathrm{Fe}$ ll complexes. $^{[14]}$ The $\mathrm{C}_{\mathrm{NHC}}-\mathrm{N}_{\text {pyridine }}-\mathrm{C}_{\mathrm{NHC}}$ ligand design cleverly exploits the fact that NHCs are strong $\sigma$-donors (Figure $3 b$ ), but at the same time takes into consideration that their $\pi$-acceptor properties are limited, and for this reason the pyridine unit is integrated to accommodate the MLCT-excited electron. Unfortunately, the ${ }^{3} \mathrm{MLCT}$ energy is nevertheless raised compared to $\left[\mathrm{Fe}(\mathrm{tpy})_{2}\right]^{2+}$ due to modest $\pi$-acceptor abilities, and this can be counteracted to some extent by increasing the $\pi$ conjugation when replacing imidazolylidene by benzimidazolylidene subunits (Figure $5 a$ ) yielding a ${ }^{3} \mathrm{MLCT}$ lifetime of 16 ps as reported by Gros, Haacke and coworkers, ${ }^{[24]}$ or by attaching carboxyl-groups to the pyridine unit. Compared to the parent complex in Figure $2 \mathrm{~d}\left(\mathrm{R}=\mathrm{CH}_{3}\right)$, the carboxylfunctionalized complex in Figure $5 b\left(\mathrm{R}=\mathrm{CH}_{3}\right)$ has its MLCT absorption maximum red-shifted by ca. $2000 \mathrm{~cm}^{-1}$, and its ${ }^{3} \mathrm{MLCT}$ lifetime is lengthened from 9 ps to $16-18$ ps in acetonitrile, ${ }^{[25]}$ or 37 ps on $\mathrm{Al}_{2} \mathrm{O}_{3}$ nanofilm. ${ }^{[25 b]}$ When attached to $\mathrm{TiO}_{2}$, this photoexcited complex injects electrons into the conduction band with a time constant of 3.1 ps and a $92 \%$ conversion of photons to electrons, but unfortunately only $13 \%$ of the resulting charge- 
separated states persist on the nanosecond timescale. ${ }^{[25 b]}$ This could be a reason for the modest performance of a dye-sensitized solar cell device with this particular sensitizer reported by Gros, Haacke, and coworkers. ${ }^{[25 a]}$ Subsequent studies by the same group including a heteroleptic Fe" $-\mathrm{NHC}$ complex provided similar results with regard to photovoltaic efficiency in sensitized solar cells. ${ }^{[26]}$ However, computational work by Persson and coworkers found that $\mathrm{Fe}^{\prime l}$ complexes with $\mathrm{C}_{\mathrm{NHC}}-\mathrm{N}_{\text {pyridine }}-\mathrm{C}_{\mathrm{NHC}}$ ligands have intrinsic electronic properties well-suited to promote chargeseparation through very rapid ( $100 \mathrm{fs}$ ) electron injection into the conduction band of $\mathrm{TiO}_{2} \cdot{ }^{[27]} \mathrm{A}$ computational perspective of $\mathrm{Fe}^{\mathrm{II}}$ polypyridines as dyes in solar cells has been published recently by Jakubikova and coworkers. ${ }^{[28]}$

An alternative strategy to keeping the ${ }^{3} \mathrm{MLCT}$ energy low while still exploiting the strong $\sigma$-donation provided by $\mathrm{NHC}$ ligands is the synthesis of heteroleptic complexes, in which a $\mathrm{C}_{\mathrm{NHC}}-\mathrm{N}_{\text {pyridine }}-\mathrm{C}_{\mathrm{NHC}}$ chelator is combined with a traditional polypyridine ligand such as tpy. ${ }^{[29]}$ A complex of this type (Figure $5 \mathrm{c}$ ) has been used by Bauer and coworkers for photosensitization of water reduction. ${ }^{[30]}$ The bulky diisopropylphenyl (dipp) substituents used in this case prevent formation of homoleptic $\mathrm{C}_{\mathrm{NHC}}-\mathrm{N}_{\text {pyridine }}-\mathrm{C}_{\mathrm{NHC}}$ complexes. (a)

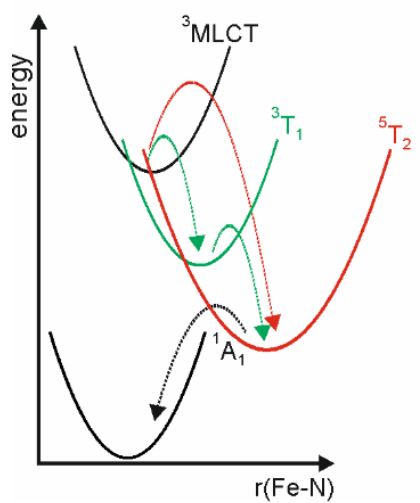

(b)

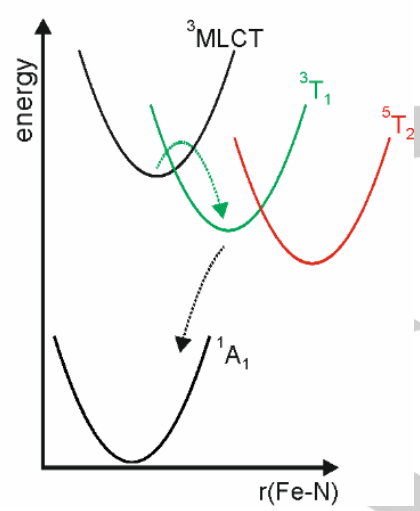

Figure 6. Simplified schematic representations of ${ }^{3} \mathrm{MLCT}$ relaxation pathways in classic $\mathrm{Fe}^{\text {Il }}$ polypyridine complexes such as $\left[\mathrm{Fe}(\mathrm{bpy})_{3}\right]^{2+}$ and $\left[\mathrm{Fe}(\mathrm{tpy})_{2}\right]^{2+}(\mathrm{a})$ $[7 \mathrm{a}, 7 \mathrm{~b}]$ and in Fell NHC complexes (b). ${ }^{[14,31]}$

The $\mathrm{N}$-substituents themselves have an important influence on the ligand field strength and the achievable ${ }^{3} \mathrm{MLCT}$ lifetime, particularly in homoleptic complexes with the basic structure shown in Figure $2 \mathrm{~d}$. According to $\mathrm{X}$-ray crystallographic studies, the Fe-C bonds are $0.13 \AA$ shorter in the complex with $\mathrm{R}=\mathrm{CH}_{3}$ than for $\mathrm{R}={ }^{t} \mathrm{Bu}$, because of the steric repulsion between the ${ }^{t} \mathrm{Bu}$ groups of one ligand with the pyridine moiety of the other. ${ }^{[14]}$ Consequently, the ligand field in the complex with $\mathrm{R}={ }^{t} \mathrm{Bu}$ is weaker and the ${ }^{3} \mathrm{MLCT}$ lifetime is considerably shorter ( $\sim 0.3 \mathrm{ps}$ for $\mathrm{R}={ }^{t} \mathrm{Bu}$ compared to $9 \mathrm{ps}$ for $\mathrm{R}=\mathrm{CH}_{3}$ ). For $\mathrm{R}={ }^{i} \mathrm{Pr}, \mathrm{a}{ }^{3} \mathrm{MLCT}$ lifetime of 8.1 ps was found, ${ }^{[16]}$ hence there is some correlation between the size of $\mathrm{R}$ and the ${ }^{3} \mathrm{MLCT}$ lifetime. Bauer and coworkers further established a correlation between $\mathrm{NHC}$ donor count and photophysical properties of Fell complexes. ${ }^{[16]}$ The sterically most congested complex $\left(R={ }^{t} \mathrm{Bu}\right.$ in Figure $\left.2 \mathrm{~d}\right)$ exhibiting the shortest ${ }^{3} \mathrm{MLCT}$ lifetime ( $0.3 \mathrm{ps}$ ) was recently explored by time-resolved X-ray scattering in combination with DFT. ${ }^{[15]}$ After MLCT-excitation of this complex, its ${ }^{5} \mathrm{~T}_{2}$ state at an energy of $0.75 \mathrm{eV}$ is rapidly populated and then decays to the ground state with a lifetime of $260 \mathrm{ps}$. The key finding is that the metal-ligand bonds are very strongly elongated in this ${ }^{5} \mathrm{~T}_{2}$ state. Compared to the ${ }^{1} \mathrm{~A}_{1}$ ground state, the axial Fe-N bonds are longer by $0.29 \AA$ whilst the equatorial $\mathrm{Fe}-\mathrm{C}$ distances increase by $0.21 \AA .{ }^{[15]}$ For the structurally related complex with $\mathrm{R}=\mathrm{CH}_{3}$ (Figure $2 \mathrm{~d}$ ) even more significant elongations of $0.34 \AA$ (for axial $\mathrm{Fe}-\mathrm{N}$ bonds) and $0.25 \AA$ (for equatorial $\mathrm{Fe}-\mathrm{C}$ bonds) were calculated for the ${ }^{5} \mathrm{~T}_{2}$ state. ${ }^{[15,31]}$ In this case, the ${ }^{3} \mathrm{MLCT}$ lifetime is $9 \mathrm{ps}$ as noted above, and there is no experimental evidence for population of the highly distorted ${ }^{5} \mathrm{~T}_{2 \mathrm{~g}}$ in the course of ${ }^{3} \mathrm{MLCT}$ deactivation. This contrasts the frequently invoked ${ }^{3} \mathrm{MLCT} \rightarrow{ }^{3} \mathrm{MC}$ $\rightarrow{ }^{5} \mathrm{MC}$ or ${ }^{3} \mathrm{MLCT} \rightarrow{ }^{5} \mathrm{MC}$ relaxation pathways for $\left[\mathrm{Fe}(\mathrm{bpy})_{3}\right]^{2+}$ and $\left[\mathrm{Fe}(\mathrm{tpy})_{2}\right]^{2+}$ (Figure 6a), and is due to the unusually large structural distortions required to access the ${ }^{5} \mathrm{MC}$ state in the carbene complexes. Instead, the calculations combined with experiments clearly indicate a ${ }^{3} \mathrm{MLCT} \rightarrow{ }^{3} \mathrm{MC}$ relaxation, followed by direct deactivation of the latter into the ground state (Figure 6b), bypassing the ${ }^{5} \mathrm{MC}$ state. ${ }^{[14,31]}$

Recent computational work by Monari and coworkers demonstrated that there can be subtle but important differences in the ${ }^{3} \mathrm{MLCT}$ deactivation pathways for fac- and mer-isomers of the same Fe" carbene complex, and they concluded that the Fe$\mathrm{N}$ bond elongation is the key normal coordinate leading to triplet relaxation. ${ }^{[32]}$ Their work underscores the importance of complete calculation of the potential energy surfaces to adequately describe excited state relaxation.

The finding that the ${ }^{5} \mathrm{MC}$ state does not seem to be involved in the ${ }^{3} \mathrm{MLCT}$ deactivation of $\mathrm{Fe}^{11}$-NHC complexes is an important conceptual difference to traditional $\mathrm{Fe}^{\|}$polypyridine complexes (Figure 6). It illustrates that if an undesired MC state is sufficiently strongly distorted, then it may not play a significant role even if it lies at relatively low energy.

\section{Concept V: Stabilization of MLCT states I destabilization of MC states with cyclometalating $\sigma$ - and $\pi$-donor ligands}

The idea of using cyclometalating chelate ligands for obtaining photoactive Fe" complexes (Figure 2e) has been promoted by the computational groups of Dixon and Jakubikova, whilst experimental investigations seem to be less far advanced yet. However, some intriguing predictions have emerged from DFT and TD-DFT calculations, mostly concerning bis(tridentate complexes) with variable numbers and positions of cyclometalating phenyl units. When replacing tpy with structurally related $\mathrm{N}^{\wedge} \mathrm{N}^{\wedge} \mathrm{C}$ or $\mathrm{N}^{\wedge} \mathrm{C}^{\wedge} \mathrm{N}$ ligands such as those shown in Figure 2e/7a, MLCT states are strongly stabilized (ca. $1 \mathrm{eV}$ ) due to the pronounced $\pi$-donating character of the cyclometalating ligands (Figure $3 d),{ }^{[17 b]}$ leading to a red-shift of the respective absorption bands. ${ }^{[17 \mathrm{c}]}{ }^{3} \mathrm{MC}$ states are less influenced by cyclometalation (ca. $0.2 \mathrm{eV}$ ), implying that the destabilization of the $e_{g}$ orbitals by $\sigma$ donation (Figure $3 \mathrm{~b}$ ) is of similar magnitude as the destabilization of the $t_{2 g}$ orbitals by $\pi$-donation (Figure $3 d$ ). ${ }^{[17 b]}$ However, the 
photophysically most relevant ${ }^{3} \mathrm{MC}$ state is destabilized only when the ligating $\mathrm{C}$-atoms are on one of the peripheral rings of the tridentate ligand, but when instead they are on the central ring an undesirable stabilization of ${ }^{3} \mathrm{MC}$ results. ${ }^{[17 \mathrm{~b},}{ }^{33]}$ The complexes shown in Figure 2e/7a were therefore identified as particularly promising with regard to avoiding the population of the ${ }^{3} \mathrm{MC}$ state out of the ${ }^{3} \mathrm{MLCT}$ state. ${ }^{[17 \mathrm{~b}, 17 \mathrm{c}]}$ Cyclometalation increases the energy difference between the ${ }^{1} \mathrm{~A}_{1}$ and ${ }^{5} \mathrm{~T}$ states by $8-19 \mathrm{kcal} / \mathrm{mol}$, with the amount of stabilization depending on the number and position (center or side) of the aryl groups. ${ }^{[17 a]}$ Overall, these calculations all predict that cyclometalation has the potential to slow relaxation from the ${ }^{1 / 3} \mathrm{MLCT}$ states into the ${ }^{3} \mathrm{MC}$ and ${ }^{5} \mathrm{MC}$ states. ${ }^{[17]}$ On the other hand, experimental work by Heinze and coworkers found that cyclometalating ligands lead to $\mathrm{Ru}^{\prime \prime}$ complexes that are less useful than anticipated, exhibiting only very weak photoluminescence in solution at room temperature. ${ }^{[34]}$

(a)
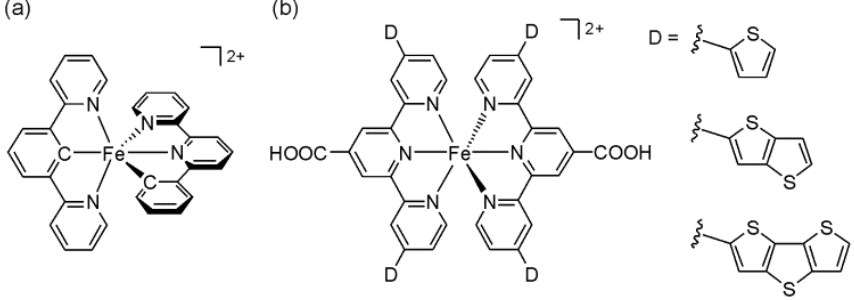

Figure 7. Exemplary candidate complexes predicted to be interesting by calculations: (a) $\left[\mathrm{Fe}\left(\mathrm{N}^{\wedge} \mathrm{C}^{\wedge} \mathrm{N}\right)\left(\mathrm{N}^{\wedge} \mathrm{N}^{\wedge} \mathrm{C}\right)\right] ;[17 \mathrm{a}, 17 \mathrm{~b}]$ (b) complexes with $\pi$-donating ligands, some of them leading to "HOMO inversion".[35]

Dixon and coworkers noted that only up to two pyridine ligands can be replaced by phenyl-units, otherwise the iron center would no longer be in the +1 oxidation state. ${ }^{[17 c]}$ This is an interesting aspect in view of the very recent discovery of photoluminescence from two Fe ${ }^{\text {III }}$ complexes (see below). A recent DFT study by Jakubikova and coworkers addressed the issue of oxidative stability of cyclometalated Fe"l complexes. ${ }^{[36]}$

Complementary work aimed to computationally identify ligands that might provide $\mathrm{Fe}^{\| l}$ complexes in which ${ }^{3} \mathrm{MLCT}$ states are energetically lower than ${ }^{3} \mathrm{MC}$ states. In addition to NHC-type (chelate) ligands, strongly $\sigma$-donating acetylide-based systems seemed particularly promising. ${ }^{[37]}$

Very recently, Jakubikova and coworkers reported on a computational study focused on improving the optical absorption properties of $\mathrm{Fe}^{\| l}$ polypyridines, and this work provided particularly interesting insights regarding the importance of the $\pi$-donation properties of the ligands. ${ }^{[35]}$ Tpy ligands substituted with furan, thiophene and selenophenes (Figure $7 \mathrm{~b}$ ) were found to have occupied $\pi$-orbitals that are energetically better aligned with the $\mathrm{t}_{2 \mathrm{~g}}$ orbitals on $\mathrm{Fe}^{\prime \prime}$, leading to stronger metal-ligand $\pi$-interactions and a consequent increase of the HOMO energy (Figure 3d). This results in multiple mixed MLCT/ILCT (ILCT = intra-ligand charge transfer) transitions in the calculated absorption spectrum. When donor groups with more extended $\pi$-conjugation are attached to tpy (e. g., thienothiophene, dithienothiophene), further stabilization of the ligand $\pi$-orbitals results in a ligand-centered HOMO, and this effect has been termed "HOMO inversion". [35]
This is conceptually very interesting, yet at this point it seems unclear how relaxation of the resulting low-lying LLCT excited states will take place, in particular how competitive radiative processes will be.

Experimental work by Dietzek, Schubert and coworkers demonstrated that the use of tpy ligands with extended $\pi$ conjugated groups in 4'-position can represent a viable strategy to obtaining relatively long-lived ${ }^{3} \mathrm{MLCT}$ states in $\left[\mathrm{Fe}(\text { tpy })_{2}\right]^{2+}$ compounds. ${ }^{[38]}$ In a molecular triad comprised of a central $\left[\mathrm{Fe}(\mathrm{tpy})_{2}\right]^{2+}$ unit flanked by two peripheral $\left[\mathrm{Ru}(\mathrm{tpy})_{2}\right]^{2+}$ chromophores via $p$-phenylene vinylene linkers, $a^{3} \mathrm{MLCT}$ lifetime of 26 ps was measured for the central Fe" unit. ${ }^{[38]}$

\section{Concept VI: Combined strong $\sigma$-donation and $\pi$-acceptance with mesoionic carbene ligands}

$\mathrm{NHC}$ ligands are strong $\sigma$-donors but relatively weak $\pi$-acceptors (section 5). Wärnmark, Sundström, and coworkers found that the mesoionic carbene ligand 4,4'-bis(1,2,3-tri-azol-5-ylidene) (btz) (Figure 2f/8) acts both as a stronger $\sigma$-donor and $\pi$-acceptor than classic NHCs. ${ }^{[39]}$ The uncommon $\mathrm{Fe}(\mathrm{bpy}) \mathrm{Cl}_{2}$ intermediate gave access to the heteroleptic $\left[\mathrm{Fe}(\mathrm{btz})_{2}(\mathrm{bpy})\right]^{2+}$ complex (Figure 8a) with $\mathrm{a}^{3} \mathrm{MLCT}$ lifetime of $13 \mathrm{ps}$, one hundred times longer than in $\left[\mathrm{Fe}(\mathrm{bpy})_{3}\right]^{2+}$. The new complex is photochemically robust even during overnight laser experiments. ${ }^{[39]}$ Compared to normal $\mathrm{NHC}$ ligands, btz has a formal negative charge on the carbene $\mathrm{C}$-atom in one resonance structure, ${ }^{[40]}$ and on this basis it becomes readily understandable why btz is a stronger $\sigma$-donor. At the same time, the increased number of $\mathrm{N}$ atoms lowers its $\pi^{*}$ energy compared to normal NHC ligands, making it a stronger $\pi$-acceptor (Figure 3c). ${ }^{[39]}$ In the very strong ligand field imposed by btz, the ${ }^{3} \mathrm{MC}$ and ${ }^{5} \mathrm{MC}$ states are destabilized and their minima displaced far away from that of the ${ }^{3} \mathrm{MLCT}$ state, making undesired nonradiative relaxation comparatively inefficient. (a)

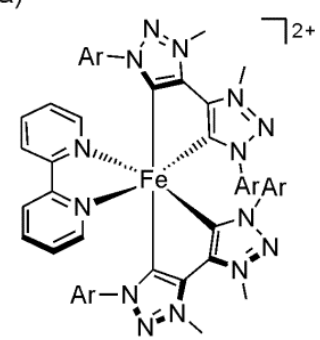

(b)

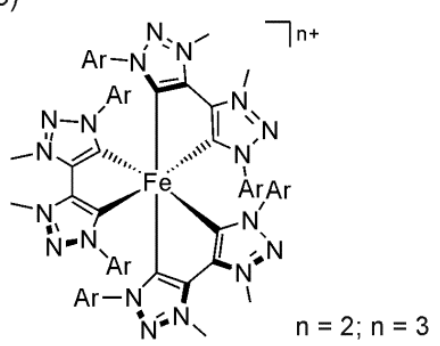

Figure 8. $\mathrm{Fe}^{\mathrm{II}}$ and $\mathrm{Fe}^{\mathrm{III}}$ complexes with mesoionic carbene ligands: (a) $\left[\mathrm{Fe}(\mathrm{btz})_{2}(\mathrm{bpy})\right]^{2+} ;{ }^{[39]}(\mathrm{b})\left[\mathrm{Fe}(\mathrm{btz})_{3}\right]^{2+}(\mathrm{n}=2) ;{ }^{[18]}\left[\mathrm{Fe}(\mathrm{btz})_{3}\right]^{3+}(\mathrm{n}=3) ;{ }^{[41]} \mathrm{Ar}=p-\mathrm{C}_{6} \mathrm{H}_{4-}$ $\mathrm{Me}$.

In the homoleptic $\left[\mathrm{Fe}(\mathrm{btz})_{3}\right]^{2+}$ complex (Figure 2f, Figure 8b, $\mathrm{n}=$ 2) these effects are even more dramatic. Biexponential transient absorption kinetics with time constants of 3.6 and 528 ps were observed, and the $3.6 \mathrm{ps}$ dynamics were attributed to initial vibrational cooling or excited-state electronic transitions into 
lower-lying excited states. ${ }^{[18]}$ The 528 ps dynamics are fully compatible with ${ }^{3} \mathrm{MLCT}$ decay, showing the excited-state absorption features typically associated with an MLCT state. Given this record lifetime, some near-infrared photoluminescence could be anticipated, but this remained undetectable at a threshold of $\mathrm{ca}$. $10^{-4}$ for the luminescence quantum yield. However, in that ${ }^{3} \mathrm{MLCT}$ state ca. $1.0 \mathrm{eV}$ above the ground state, $\left[\mathrm{Fe}(\mathrm{btz})_{3}\right]^{2+}$ is a strong photoreductant with an oxidation potential of $-1.6 \mathrm{~V}$ vs. $\mathrm{Fc}^{+/ 0} \cdot{ }^{[18]}$ For reference, the oxidation potential of ${ }^{3} \mathrm{MLCT}$-excited $\left[\mathrm{Ru}(\mathrm{bpy})_{3}\right]^{2+}$ is $-1.2 \mathrm{~V}$ against the same reference electrode, ${ }^{[42]}$ hence $\left[\mathrm{Fe}(\mathrm{btz})_{3}\right]^{2+}$ would be readily useable as a photoredox catalyst.

\section{Concept VII: Fe"II instead of Fe", spin- allowed LMCT instead of spin-forbidden MLCT}

When reacting btzH ${ }^{+}$with an $\mathrm{Fe}$ "l source $\left(\mathrm{FeBr}_{2}\right)$ and base ( $\left.{ }^{\mathrm{t}} \mathrm{BuOK}\right)$ in THF followed by aqueous workup, one obtains the $\left[\mathrm{Fe}(\mathrm{btz})_{3}\right]^{3+}$ complex, not the $\left[\mathrm{Fe}(\mathrm{btz})_{3}\right]^{2+}$ compound discussed in the prior section. ${ }^{[41]}$ The latter is then amenable by reduction of the Fe ${ }^{\text {III }}$ complex with dithionite. ${ }^{[18]}$ However, the photophysical properties of the $\mathrm{Fe}^{\mathrm{III}}$ complex are even more spectacular than those of the Fell compound. $\left[\mathrm{Fe}(\mathrm{btz})_{3}\right]^{3+}$ (Figure $8 \mathrm{~b}, \mathrm{n}=3$ ) has a low-spin $3 \mathrm{~d}^{5}$ electron configuration according to Mössbauer spectroscopy, Xray absorption, and quantum chemical calculations, ${ }^{[41,43]}$ resulting in a ${ }^{2} T_{2}$ ground state (Figure 9a). This complex exhibits LMCT absorptions with band maxima at 528 and $558 \mathrm{~nm}$, in agreement with the metal reduction and ligand oxidation potentials determined by electrochemical methods. Excitation into these absorption bands leads to visible ${ }^{2} \mathrm{LMCT}$ emission with a quantum yield of $3 \cdot 10^{-4}$ in $\mathrm{CH}_{3} \mathrm{CN}$ at room temperature. ${ }^{[41]}$ Thus, an $\mathrm{Fe}^{\text {III, }}$, not an $\mathrm{Fe}^{\text {II }}$ species has quite unexpectedly become the first iron complex exhibiting photoluminescence from a charge transfer state. ${ }^{[44]}$
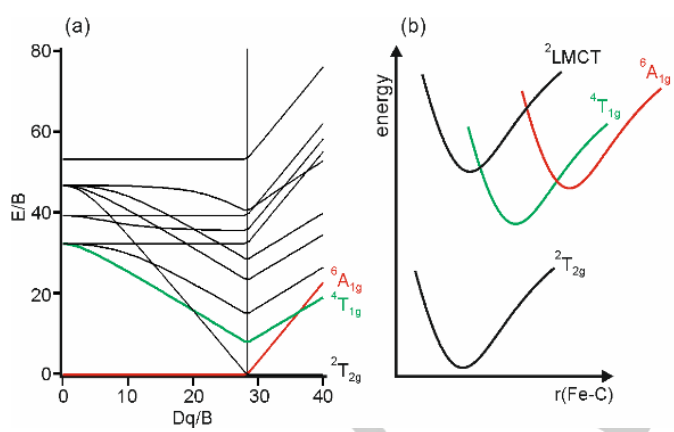

(c)

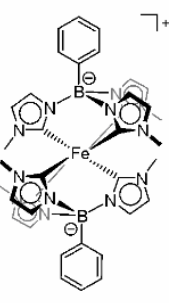

Figure 9. (a) Tanabe-Sugano diagram for the $d^{5}$ electron configuration; (b) simplified schematic potential energy diagram involving key electronic states in $\left[\mathrm{Fe}(\mathrm{btz})_{3}\right]^{3+;},[41]$ (c) molecular structure of $\left[\mathrm{Fe}(\text { phtmeimb })_{2}\right]^{+} \cdot{ }^{[45]}$

The ${ }^{2}$ LMCT decays to the ground state with a lifetime of 100 ps without observable population of MC states. When comparing the relevant parts of the Tanabe-Sugano diagrams for $d^{5}$ (Figure 9a) and $d^{6}$ electron configurations (Figure $1 e$ ), one readily recognizes some similarities with respect to $\mathrm{MC}$ states in the respective strong-field limits. In both cases, there are low-lying $M C$ states accessible either by two-electron excitation $\left({ }^{5} \mathrm{~T}_{2}\right.$ for $d^{6},{ }^{6} \mathrm{~A}_{1}$ for $\left.\mathrm{d}^{5}\right)$ or one-electron excitation $\left({ }^{3} T_{1}\right.$ for $d^{6},{ }^{4} T_{1}$ for $\left.d^{5}\right)$. Accordingly, the ${ }^{6} \mathrm{MC}$ and ${ }^{4} \mathrm{MC}$ potentials have their minima at substantially extended Fe-C bond coordinate (Figure $9 b$ ), just like the ${ }^{5} \mathrm{MC}$ and ${ }^{3} \mathrm{MC}$ states in Fe"l complexes (Figure 6b). Calculations further indicate that the ${ }^{6} \mathrm{MC}$ and ${ }^{4} \mathrm{MC}$ potential minima are at relatively high energy due to the strongly $\sigma$-donating character of btz. Moreover, the Stokes shift between ${ }^{2} \mathrm{LMCT}$ absorption and emission amounts to only $0.15 \mathrm{eV}$, indicating that the ${ }^{2} \mathrm{LMCT}$ state is only weakly distorted relative to the ground state. Thus, like for the lowest ${ }^{3} \mathrm{MLCT}$ states in many of the Fe"l complexes discussed above, there are sizeable barriers for the deactivation of the emissive ${ }^{2}$ LMCT state via MC states (Figure 9b). Based on temperature-dependent lifetime measurements, an Arrhenius model with two exponential functions yielded activation barriers of 4 and $22 \mathrm{~kJ} / \mathrm{mol} .{ }^{[41]}$

Aside from the direction of the optical charge transfer, there is yet another major difference to $\mathrm{Fe}^{\mathrm{ll}}$ complexes. The MLCT states of key interest in the latter are spin triplets, and radiative rate constants for luminescence to the singlet ground state are expected to be relatively small, because of the spin-forbidden (phosphorescence-type) nature of the process. By contrast, emission from the ${ }^{2} \mathrm{LMCT}$ state to the ${ }^{2} \mathrm{~T}_{2}$ ground state in $\left[\mathrm{Fe}(\mathrm{btz})_{3}\right]^{3+}$ is a spin-allowed (fluorescence-type) process, making radiative relaxation inherently more competitive with nonradiative deactivation. Specifically, a radiative rate constant of $3 \cdot 10^{6} \mathrm{~s}^{-1}$ was determined for the ${ }^{2} \mathrm{LMCT} \rightarrow{ }^{2} \mathrm{~T}_{2}$ transition in $\left[\mathrm{Fe}(\mathrm{btz})_{3}\right]^{3+}$.

These highly interesting findings were recently topped by a study of the same Swedish-Danish consortium, reporting on roomtemperature photoluminescence from a ${ }^{2} \mathrm{LMCT}$ state with a lifetime of $2.2 \mathrm{~ns}$ and a quantum yield of $2 \% .{ }^{[45]}$ This is a truly amazing result, and it motivated the title of this Concept article. The $\left[\mathrm{Fe}(\text { phtmeimb })_{2}\right]^{+}$complex (Figure 9c) has two anionic scorpionate-like tris(carbene) ligands, which were previously used by Reber and coworkers to obtain a structurally related $\mathrm{Mn}^{\mathrm{V}}$ complex that exhibited weak LMCT luminescence in the solid state. ${ }^{[46]}$ A variant of this borate ligand had been employed earlier by Fehlhammer for a homoleptic Fe ${ }^{\text {III }}$ complex, ${ }^{[47]}$ but luminescence properties were not explored at that time (and likely would not be spectacular due to the presence of an $\mathrm{H}$-atom at boron instead of a phenyl-ring like in phtmeimb). The anionic nature of this scorpionate ligand combined with the near-perfect octahedral NHC coordination of Fe $\mathrm{F}^{\mathrm{III}}$ induces a particularly strong ligand field, in which the metal center has low-spin $\mathrm{d}^{5}$ electron configuration, analogous to $\left[\mathrm{Fe}(\mathrm{btz})_{3}\right]^{3+}$. However, the ligand field in $\left.[\mathrm{Fe} \text { (phtmeimb })_{2}\right]^{+}$is so strong that the ${ }^{4} \mathrm{MC}$ and ${ }^{6} \mathrm{MC}$ states are further destabilized by $13 \%$ and $23 \%$ relative to $\left[\mathrm{Fe}(\mathrm{btz})_{3}\right]^{3+}$ according to DFT calculations, causing a further increase of the activation barrier for decay of the emissive ${ }^{2}$ LMCT state via the ${ }^{4} \mathrm{MC}$ state. An Arrhenius-type analysis of temperature dependent luminescence lifetimes yields an activation barrier of $3 \mathrm{~kJ} / \mathrm{mol}$ and a pre-exponential factor of $1 \cdot 10^{9} \mathrm{~s}^{-1}$. For $\left[\mathrm{Fe}(\mathrm{btz})_{3}\right]^{3+}$ larger preexponential factors of $2 \cdot 10^{10} \mathrm{~s}^{-1}$ and $2 \cdot 10^{13} \mathrm{~s}^{-1}$ were found, ${ }^{[41]}$ and therefore the longer ${ }^{2} \mathrm{LMCT}$ lifetime of $\left[\mathrm{Fe}(\text { phtmeimb })_{2}\right]^{+}(2 \mathrm{~ns}$ compared to $0.1 \mathrm{~ns}$ ) was tentatively attributed to a reduced crossing frequency from the ${ }^{2} \mathrm{LMCT}$ state to the ${ }^{4} \mathrm{MC}$ state. ${ }^{[45]}$ 
${ }^{2} \mathrm{LMCT}$-excited $\left[\mathrm{Fe}(\text { phtmeimb })_{2}\right]^{+}$is both a strong reductant $\left(\mathrm{E}_{\mathrm{ox}}=\right.$ $-1.9 \mathrm{~V}$ vs. $\left.\mathrm{Fc}^{+/ 0}\right)$ and a good oxidant $\left(\mathrm{E}_{\text {red }}=1.0 \mathrm{~V}\right.$ vs. $\left.\mathrm{Fc}^{+/ 0}\right)$. Accordingly, oxidative excited-state quenching with methyl viologen as well as reductive quenching by diphenylamine both occur with essentially diffusion-limited kinetics. ${ }^{[45]}$ In long-term photoirradiation experiments (156 hours with an $11 \mathrm{~W}$ fluorescent lamp), the $\left[\mathrm{Fe}(\text { phtmeimb })_{2}\right]^{+}$complex is remarkably robust, particularly in direct comparison to $\left[\mathrm{Ru}(\mathrm{bpy})_{3}\right]^{2+}$. The combination of respectable luminescence quantum yield, nanosecond lifetime, pronounced photoredox properties and photostability make this complex a very interesting alternative to $\mathrm{Ru}$ "l polypyridines. (a)

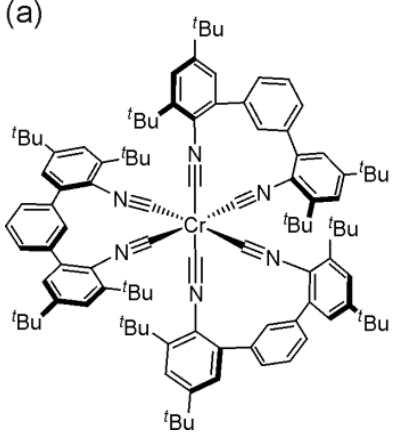

(b)

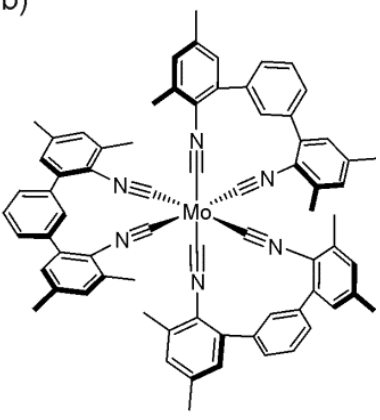

Figure 10. (a) $\mathrm{Cr}^{0}$ complex with low-spin $3 d^{6}$ electron configuration (isoelectronic to $\left[\mathrm{Fe}(\mathrm{bpy})_{3}\right]^{2+}$ ) exhibiting ${ }^{3} \mathrm{MLCT}$ luminescence; ${ }^{[48]}$ (b) $\mathrm{Mo}^{0}$ complex with low-spin $4 d^{6}$ electron configuration (isoelectronic to $\left[R u(b p y)_{3}\right]^{2+}$ ) exhibiting ${ }^{3} \mathrm{MLCT}$ luminescence. ${ }^{[49]}$

\section{Isoelectronic alternatives to $\mathrm{Fe}^{\mathrm{Il}}$ as ${ }^{3} \mathrm{MLCT}$ emitters: $\mathrm{Cr}^{0}$ and $\mathrm{Mo}^{\circ}$}

There are now two Fe'll complexes with a photoactive ${ }^{2}$ LMCT state that are promising for hole injection into p-type semiconductor photocathodes. ${ }^{[41,45]}$ However, there is still no report of ${ }^{3} \mathrm{MLCT}$ luminescence from an Fe" complex, and longlived MLCT states are desirable for electron injection into n-type semiconductor photoanodes. ${ }^{[23 \mathrm{~b}, 25 \mathrm{~b}]}$ Whilst the $528-\mathrm{ps}{ }^{3} \mathrm{MLCT}$ lifetime of $\left[\mathrm{Fe}(\mathrm{btz})_{3}\right]^{2+}$ seems promising and could in fact be useful for tandem cells operating with the $\left[\mathrm{Fe}(\mathrm{btz})_{3}\right]^{2+} /\left[\mathrm{Fe}(\mathrm{btz})_{3}\right]^{3+}$ redox couple, it seems useful to consider alternatives to $\mathrm{Fe}^{\| 1}$ with the $\mathrm{d}^{6}$ valence electron configuration, in particular $3 d^{6}$ and $4 d^{6} .{ }^{[50]}$

Recently, we synthesized and explored a $\mathrm{Cr}^{0}$ complex with chelating diisocyanide ligands (Figure 10a), which has a low-spin $3 d^{6}$ electron configuration due to the strong ligand field provided by the isocyanides. ${ }^{[48]}$ This complex luminesces $\left(\lambda_{\max }=630 \mathrm{~nm}\right)$ from a ${ }^{3} \mathrm{MLCT}$ state with a quantum yield of $10^{-5}$ and a lifetime of $2.2 \mathrm{~ns}$ in de-aerated THF at room temperature. To our knowledge, this is the first $3 d^{6}$ complex exhibiting MLCT luminescence in solution at room temperature, ${ }^{[51]}$ and its properties can likely be further enhanced through improved ligand design. The complex from Figure 10a was used for sensitized triplet-triplet annihilation upconversion with anthracene, demonstrating that bimolecular reactions are possible with its ${ }^{3} \mathrm{MLCT}$ state..$^{[52]}$

$\mathrm{A} \mathrm{Mo}^{\circ}$ complex with similar diisocyanide chelate ligands (Figure 10b) exhibits far better properties than its $\mathrm{Cr}^{0}$ analogue, ${ }^{[49]}$ presumably because the $4 \mathrm{~d}^{6}$ species $\mathrm{Mo}^{0}$ experiences a substantially stronger ligand field than the $3 d^{6}$ species $\mathrm{Cr}^{0}$ in a similar coordination environment. ${ }^{3} \mathrm{MLCT}$ luminescence from the $\mathrm{Mo}^{\circ}$ complex occurs with a quantum yield of 0.045 and a lifetime of $225 \mathrm{~ns}$ in de-aerated benzene. In this long-lived excited state, its oxidation potential is $-2.5 \mathrm{~V}$ vs. $\mathrm{Fc}^{+/ 0}$, making it a more potent photoreductant than the widely used fac- $[\operatorname{Ir}(\mathrm{ppy})]_{3}$ complex, ${ }^{[42]}$ and this was exploited for thermodynamically challenging photoredox catalysis. ${ }^{[49]}$ These $\mathrm{Cr}^{0}$ and $\mathrm{Mo}^{0}$ studies with chelating diisocyanides were inspired by prior work on $\mathrm{W}^{0}$ by the Gray group with monodentate isocyanides. ${ }^{[52-53]}$ The natural abundance of $\mathrm{Cr}$ and $\mathrm{Mo}$ is significantly lower than that of $\mathrm{Fe}$, yet $\mathrm{Cr}$ is twice as abundant in Earth's crust than the frequently considered $\mathrm{Cu}$ (0.01 vs. 0.005 mass percent). ${ }^{[54]}$

DFT studies by Uhlig, Persson and coworkers indicate that Co ${ }^{\prime \prime \prime}$ carbene complexes have interesting electronic structures, ${ }^{[43]}$ and recent work by Zysman-Colman and Hanan identified two emissive CollI complexes which furthermore were used for photoredox catalysis. ${ }^{[55]}$ However, these are LMCT emitters, i. e., the direction of charge transfer is the same as in the Fe $\mathrm{F}^{\text {III }}$ complexes discussed above. Similarly, the $\mathrm{Zr}^{\mathrm{IV}}$ luminophores and photocatalysts reported recently by Milsmann and coworkers operate on the basis of LMCT excitations. ${ }^{[56]}$

\section{Concluding remarks}

The 7 different concepts used to structure this survey of recent progress on photoactive iron complexes can be condensed to 2 overarching strategies that will likely continue to be of universal importance: (i) the use of chelating ligands that permit robust metal coordination in high symmetry, as closely to the ideal octahedral coordination as possible, in order to maximize the overlap between metal and ligand orbitals; (ii) the use of ligands that combine strong $\sigma$-donor and $\pi$-acceptor properties in order to create strong ligand fields, in which nonradiatively deactivating MC states are shifted to high energies and displaced strongly along relevant normal coordinates. Both of these strategies directly emerge from ligand field theory and as such are not novel, but many of the recent studies discussed above reported on very effective ways to implement these strategies, and some rather clear ligand design principles have now been elaborated, both experimentally and computationally.

It seems fair to state that the very recent discovery of LMCTemissive Fe ${ }^{\text {III }}$ complexes came as a big surprise for many active researchers of the inorganic photophysics community, and this could be considered a disruptive change, to use a term from economy. Fe $\mathrm{e}^{\text {III }}$ complexes are likely to attract much attention from this community in the near future, considering that the necessary ligand design principles have now become so evident. The recently reported $\mathrm{Fe}^{\mathrm{III}}$ complex with the anionic scorpionate tris(NHC) ligand exhibits photophysical and photochemical properties which in several regards come very close to those of the prototype $\left[\mathrm{Ru}(\mathrm{bpy})_{3}\right]^{2+}$ complex, and in terms of photorobustness seems to be even better. ${ }^{[45]}$ It remains to be seen whether the electronic structures of photoactive Fe ${ }^{\text {III }}$ complexes 
will be as widely and as readily tunable as those as $\mathrm{Ru}^{\prime \prime}$ polypyridines. Heteroleptic Fe ${ }^{\text {III }}$ complexes could be interesting targets for separate tuning of HOMO and LUMO energies, ${ }^{[12]}$ similar to what is possible in cyclometalated Ir ${ }^{\text {III }}$ complexes. ${ }^{[57]}$ The idea of targeting spin-allowed LMCT rather than spinforbidden MLCT emission is fundamentally interesting and has perhaps received too little attention until now. Whether or not a spin change is involved will obviously greatly affect radiative relaxation rates and the competition between luminescence and nonradiative deactivation. For the classic LMCT target cases such as the $d^{0}$ (e. g., Z $\mathrm{r}^{\mathrm{lv}}{ }^{[56]}$ ) or low-spin $\mathrm{d}^{6}$ electron configurations (e. g., Co ${ }^{\text {III }}{ }^{[55]}$ spin-forbidden emission is found, hence the low-spin $\mathrm{d}^{5}$ configuration is special in that regard, but there exist other electron configurations for which similar behavior could be expected.

Regardless of the spin issue, further consideration of LMCT and less focus on MLCT excited-states could be a possible future development as well. Particularly organic photoredox catalysis largely relied on MLCT excited states when using metal-based sensitizers until now, but there are very promising avenues involving LMCT excited states. ${ }^{[58]}$ Reversal of the charge transfer direction from MLCT to LMCT leads to sensitizers which will be better suited for hole injection into $p$-type semiconductors than for electron injection into n-type semiconductors. To date, there has been no report of an MLCT-emitter based on Fe", but an isoelectronic $\mathrm{Cr}^{0}$ complex was recently found to be luminescent with a ${ }^{3} \mathrm{MLCT}$ lifetime of $2.2 \mathrm{~ns}$ in fluid solution at room temperature. ${ }^{[48]}$ Research along these lines, considering other Earth-abundant metal elements with the $3 d^{6}$ (or $\left.4 d^{6}\right)^{[49]}$ electron configuration could be an interesting avenue. Exciting times are ahead in the photophysics and the photochemistry of transition metal complexes, and in some years from now we will more clearly see whether iron can indeed become the new ruthenium in these areas. A big leap forward in that direction has been made very recently.

\section{Acknowledgements}

The author thanks his co-workers for their contributions to the research performed by his group cited in this article. Their names appear in the references. Support from the Swiss National Science Foundation, currently through grant number 200021_178760 and the NCCR Molecular Systems Engineering, is gratefully acknowledged.

Keywords: luminescence • time-resolved spectroscopy • ligand design $\bullet$ sustainable chemistry $\bullet$ photophysics

[1] A. Juris, V. Balzani, F. Barigelletti, S. Campagna, P. Belser, A. Von Zelewsky, Coord. Chem. Rev. 1988, 84, 85-277.

[2] N. H. Damrauer, G. Cerullo, A. Yeh, T. R. Boussie, C. V. Shank, J. K. McCusker, Science 1997, 275, 54-57.

[3] Q. C. Sun, S. Mosquera-Vazquez, Y. Suffren, J. Hankache, N. Amstutz, L. M. L. Daku, E. Vauthey, A. Hauser, Coord. Chem. Rev. 2015, 282, 8799.

[4] Q. C. Sun, B. Dereka, E. Vauthey, L. M. L. Daku, A. Hauser, Chem. Sci. 2017, 8, 223-230.
[5] E. A. Medlycott, G. S. Hanan, Chem. Soc. Rev. 2005, 34, 133-142.

[6] E. A. Juban, A. L. Smeigh, J. E. Monat, J. K. McCusker, Coord. Chem. Rev. 2006, 250, 1783-1791.

[7] a) A. Cannizzo, C. J. Milne, C. Consani, W. Gawelda, C. Bressler, F. van Mourik, M. Chergui, Coord. Chem. Rev. 2010, 254, 2677-2686; b) W. K. Zhang, K. J. Gaffney, Acc. Chem. Res. 2015, 48, 1140-1148; c) G. Auböck, M. Chergui, Nat. Chem. 2015, 7, 629-633.

[8] a) A. Gualandi, M. Marchini, L. Mengozzi, M. Natali, M. Lucarini, P. Ceroni, P. G. Cozzi, ACS Catal. 2015, 5, 5927-5931; b) S. ParisienCollette, A. C. Hernandez-Perez, S. K. Collins, Org. Lett. 2016, 18, 4994 4997; c) C. B. Larsen, O. S. Wenger, Chem.-Eur. J. 2018, 24, 2039-2058

[9] J. V. Caspar, T. J. Meyer, J. Phys. Chem. 1983, 87, 952-957.

[10] M. C. Carey, S. L. Adelman, J. K. McCusker, Chem. Sci. 2019, 10, 134144.

[11] L. L. Jamula, A. M. Brown, D. Guo, J. K. McCusker, Inorg. Chem. 2014, 53, 15-17.

[12] A. K. C. Mengel, C. Förster, A. Breivogel, K. Mack, J. R. Ochsmann, F Laquai, V. Ksenofontov, K. Heinze, Chem.-Eur. J. 2015, 21, 704-714.

[13] a) S. M. Fatur, S. G. Shepard, R. F. Higgins, M. P. Shores, N. H. Damrauer, J. Am. Chem. Soc. 2017, 139, 4493-4505; b) S. G. Shepard, S. M. Fatur, A. K. Rappe, N. H. Damrauer, J. Am. Chem. Soc. 2016, 138, 2949-2952.

[14] Y. Z. Liu, T. Harlang, S. E. Canton, P. Chabera, K. Suarez-Alcantara, A. Fleckhaus, D. A. Vithanage, E. Goransson, A. Corani, R. Lomoth, V. Sundström, K. Wärnmark, Chem. Commun. 2013, 49, 6412-6414.

[15] D. Leshchev, T. C. B. Harlang, L. A. Fredin, D. Khakhulin, Y. Z. Liu, E. Biasin, M. G. Laursen, G. E. Newby, K. Haldrup, M. M. Nielsen, K. Wärnmark, V. Sundström, P. Persson, K. S. Kjaer, M. Wulff, Chem. Sci. 2018, 9, 405-414.

[16] P. Zimmer, L. Burkhardt, A. Friedrich, J. Steube, A. Neuba, R. Schepper, P. Müller, U. Florke, M. Huber, S. Lochbrunner, M. Bauer, Inorg. Chem. 2018, 57, 360-373.

[17] a) S. Mukherjee, D. N. Bowman, E. Jakubikova, Inorg. Chem. 2015, 54 560-569; b) I. M. Dixon, F. Alary, M. Boggio-Pasqua, J. L. Heully, Dalton Trans. 2015, 44, 13498-13503; c) I. M. Dixon, S. Khan, F. Alary, M Boggio-Pasqua, J. L. Heully, Dalton Trans. 2014, 43, 15898-15905.

[18] P. Chábera, K. S. Kjaer, O. Prakash, A. Honarfar, Y. Z. Liu, L. A. Fredin, T. C. B. Harlang, S. Lidin, J. Uhlig, V. Sundström, R. Lomoth, P. Persson, K. Wärnmark, J. Phys. Chem. Lett. 2018, 9, 459-463.

[19] D. N. Bowman, A. Bondarev, S. Mukherjee, E. Jakubikova, Inorg. Chem. 2015, 54, 8786-8793.

[20] C. Förster, M. Dorn, T. Reuter, S. Otto, G. Davarci, T. Reich, L. Carrella, E. Rentschler, K. Heinze, Inorganics 2018, 6, 86, 10.3390/inorganics6030086.

[21] A. K. C. Mengel, C. Bissinger, M. Dorn, O. Back, C. Förster, K. Heinze, Chem.-Eur. J. 2017, 23, 7920-7931.

[22] A. Cannizzo, A. M. Blanco-Rodriguez, A. El Nahhas, J. Šebera, S. Záliš, A. Vlček, M. Chergui, J. Am. Chem. Soc. 2008, 130, 8967-8974.

[23] a) Y. Z. Liu, P. Persson, V. Sundström, K. Wärnmark, Acc. Chem. Res. 2016, 49, 1477-1485; b) T. Duchanois, L. Liu, M. Pastore, A. Monari, C. Cebrian, Y. Trolez, M. Darari, K. Magra, A. Frances-Monerris, E. Domenichini, M. Beley, X. Assfeld, S. Haacke, P. C. Gros, Inorganics 2018, 6, 63, doi: 10.3390/inorganics6020063.

[24] L. Liu, T. Duchanois, T. Etienne, A. Monari, M. Beley, X. Assfeld, S. Haacke, P. C. Gros, Phys. Chem. Chem. Phys. 2016, 18, 12550-12556.

[25] a) T. Duchanois, T. Etienne, C. Cebrian, L. Liu, A. Monari, M. Beley, X. Assfeld, S. Haacke, P. C. Gros, Eur. J. Inorg. Chem. 2015, 2469-2477; b) T. C. B. Harlang, Y. Z. Liu, O. Gordivska, L. A. Fredin, C. S. Ponseca P. Huang, P. Chabera, K. S. Kjaer, H. Mateos, J. Uhlig, R. Lomoth, R. Wallenberg, S. Styring, P. Persson, V. Sundström, K. Wärnmark, Nat. Chem. 2015, 7, 883-889.

[26] M. Pastore, T. Duchanois, L. Liu, A. Monari, X. Assfeld, S. Haacke, P. C. Gros, Phys. Chem. Chem. Phys. 2016, 18, 28069-28081.

[27] L. A. Fredin, K. Wärnmark, V. Sundström, P. Persson, ChemSusChem 2016, 9, 667-675. 
[28] E. Jakubikova, D. N. Bowman, Acc. Chem. Res. 2015, 48, 1441-1449.

[29] T. Duchanois, T. Etienne, M. Beley, X. Assfeld, E. A. Perpete, A. Monari, P. C. Gros, Eur. J. Inorg. Chem. 2014, 3747-3753.

[30] P. Zimmer, P. Müller, L. Burkhardt, R. Schepper, A. Neuba, J. Steube, F. Dietrich, U. Flörke, S. Mangold, M. Gerhards, M. Bauer, Eur. J. Inorg. Chem. 2017, 1504-1509.

[31] L. A. Fredin, M. Papai, E. Rozsalyi, G. Vanko, K. Wärnmark, V. Sundström, P. Persson, J. Phys. Chem. Lett. 2014, 5, 2066-2071.

[32] A. Frances-Monerris, K. Magra, M. Darari, C. Cebrian, M. Beley, E. Domenichini, S. Haacke, M. Pastore, X. Assfeld, P. C. Gros, A. Monari, Inorg. Chem. 2018, 57, 10431-10441.

[33] I. M. Dixon, F. Alary, M. Boggio-Pasqua, J. L. Heully, Inorg. Chem. 2013, 52, 13369-13374.

[34] a) C. Kreitner, K. Heinze, Dalton Trans. 2016, 45, 13631-13647; b) C. Kreitner, E. Erdmann, W. W. Seidel, K. Heinze, Inorg. Chem. 2015, 54, 11088-11104.

[35] S. Mukherjee, D. E. Torres, E. Jakubikova, Chem. Sci. 2017, 8, 81158126.

[36] D. C. Ashley, S. Mukherjee, E. Jakubikova, Dalton Trans. 2018, doi: 10.1039/c8dt04402c

[37] I. M. Dixon, G. Boissard, H. Whyte, F. Alary, J. L. Heully, Inorg. Chem. 2016, 55, 5089-5091.

[38] M. Wächtler, J. Kübel, K. Barthelmes, A. Winter, A. Schmiedel, T. Pascher, C. Lambert, U. S. Schubert, B. Dietzek, Phys. Chem. Chem Phys. 2016, 18, 2350-2360.

[39] Y. Z. Liu, K. S. Kjaer, L. A. Fredin, P. Chabera, T. Harlang, S. E. Canton, S. Lidin, J. X. Zhang, R. Lomoth, K. E. Bergquist, P. Persson, K. Wärnmark, V. Sundström, Chem.-Eur. J. 2015, 21, 3628-3639.

[40] S. Hohloch, L. Suntrup, B. Sarkar, Organometallics 2013, 32, 7376-7385.

[41] P. Chábera, Y. Liu, O. Prakash, E. Thyrhaug, A. El Nahhas, A. Honarfar, S. Essén, L. A. Fredin, T. C. B. Harlang, K. S. Kjaer, K. Handrup, F. Ericsson, Y. Tatsuno, K. Morgan, J. Schnadt, L. Häggström, T. Ericsson, A. Sobkowiak, S. Lidin, P. Huang, S. Styring, J. Uhlig, J. Bendix, R Lomoth, V. Sundström, P. Persson, K. Wärnmark, Nature 2017, 543, 695-699.

[42] D. M. Arias-Rotondo, J. K. McCusker, Chem. Soc. Rev. 2016, 45, 58035820.

[43] F. Ericson, A. Honarfar, O. Prakash, H. Tatsuno, L. A. Fredin, K. Handrup, P. Chabera, O. Gordivska, K. S. Kjaer, Y. Z. Liu, J. Schnadt, K.
Wärnmark, V. Sundström, P. Persson, J. Uhlig, Chem. Phys. Lett. 2017, 683, 559-566

[44] B. Sarkar, L. Suntrup, Angew. Chem. Int. Ed. 2017, 56, 8938-8940.

[45] K. S. Kjær, N. Kaul, O. Prakash, P. Chábera, N. W. Rosemann, A. Honarfar, O. Gordivska, L. A. Fredin, K. E. Bergquist, L. Häggström, T. Ericsson, L. Lindh, A. Yartsev, S. Styring, P. Huang, J. Uhlig, J. Bendix, D. Strand, V. Sundström, P. Persson, R. Lomoth, W. K., Science 2018 doi: 10.1126/science.aau7160

[46] V. Baslon, J. P. Harris, C. Reber, H. E. Colmer, T. A. Jackson, A. P. Forshaw, J. M. Smith, R. A. Kinney, J. Telser, Can. J. Chem. 2017, 95 547-552.

[47] U. Kernbach, M. Ramm, P. Luger, W. P. Fehlhammer, Angew. Chem. Int Ed. 1996, 35, 310-312.

[48] L. A. Büldt, X. Guo, R. Vogel, A. Prescimone, O. S. Wenger, J. Am. Chem. Soc. 2017, 139, 985-992.

[49] L. A. Büldt, X. Guo, A. Prescimone, O. S. Wenger, Angew. Chem. Int. Ed. 2016, 55, 11247-11250.

[50] O. S. Wenger, J. Am. Chem. Soc. 2018, 140, 13522-13533.

[51] a) L. A. Büldt, O. S. Wenger, Chem. Sci. 2017, 8, 7359-7367; b) L. A. Büldt, O. S. Wenger, Dalton Trans. 2017, 46, 15175-15177.

[52] L. A. Büldt, O. S. Wenger, Angew. Chem. Int. Ed. 2017, 56, 5676-5682.

[53] a) K. R. Mann, H. B. Gray, G. S. Hammond, J. Am. Chem. Soc. 1977, 99 306-307; b) W. Sattler, L. M. Henling, J. R. Winkler, H. B. Gray, J. Am. Chem. Soc. 2015, 137, 1198-1205.

[54] A. F. Holleman, N. Wiberg, Lehrbuch der Anorganischen Chemie, 102th ed., Walter de Gruyter, Berlin, 2007.

[55] A. K. Pal, C. F. Li, G. S. Hanan, E. Zysman-Colman, Angew. Chem. Int Ed. 2018, 57, 8027-8031.

[56] Y. Zhang, T. S. Lee, J. L. Petersen, C. Milsmann, J. Am. Chem. Soc 2018, 140, 5934-5947.

[57] M. S. Lowry, S. Bernhard, Chem. Eur. J. 2006, 12, 7970-7977.

[58] Y. Qiao, E. J. Schelter, Acc. Chem. Res. 2018, 51, 2926-2936. 


\section{Entry for the Table of Contents}

\section{CONCEPT}

Inorganic photophysics: Key concepts to obtain long-lived chargetransfer excited-states in iron complexes are discussed; recent conceptual breakthroughs are highlighted.

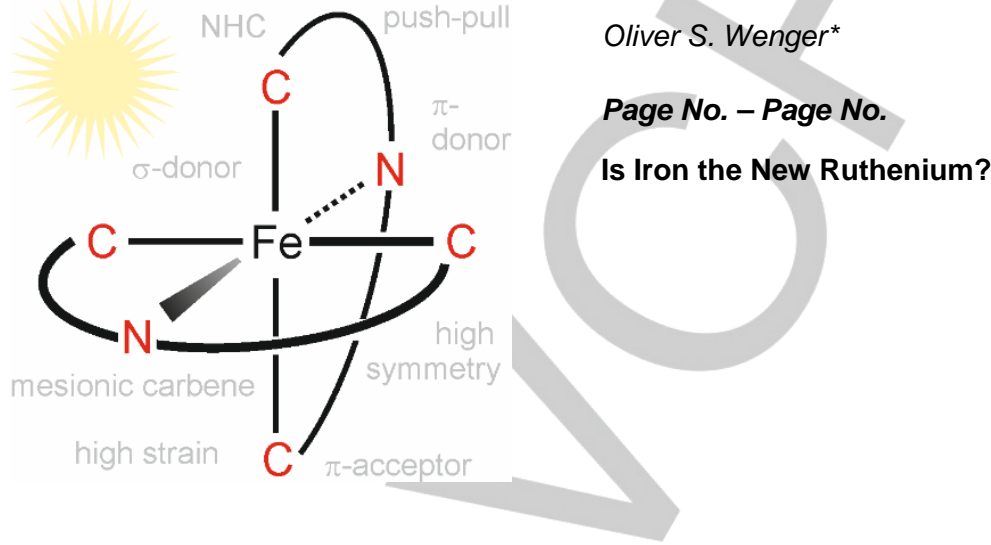

